\title{
Atividade de Glutationa S-Transferase na Degradação do Herbicida Glyphosate em Plantas de Milho (Zea mays) ${ }^{1}$
}

\author{
Glutathione S-Transferase Activity on the Degradation of the Herbicide Glyphosate in Maize \\ (Zea mays) Plants
}

CATANEO, A.C. ${ }^{2}$, DÉSTRO, G.F.G. ${ }^{3}$, FERREIRA, L.C. ${ }^{4}$, CHAMMA, K.L. ${ }^{4}$ e SOUSA, D.C.F. ${ }^{5}$

\begin{abstract}
RESUMO - A glutationa S-transferase (GST, EC 2.5.1.18) desempenha um papel importante na resposta do estresse causado por herbicidas nas plantas; é considerada uma enzima de desintoxicação, por metabolizar grande variedade de compostos xenobióticos, por meio da conjugação destes com glutationa reduzida, formando substâncias de baixa toxicidade. O milho (Zea mays) foi escolhido neste trabalho por apresentar problemas de injúrias quando submetido ao controle químico de plantas daninhas, por meio do uso de herbicidas. Esta pesquisa teve como objetivo determinar as alterações na atividade desta enzima em plantas de milho submetidas ao tratamento pelo herbicida glyphosate. O delineamento experimental utilizado foi o inteiramente casualizado, em esquema fatorial $4 x 4$, com quatro tratamentos herbicidas (glyphosate nas concentrações de $1.000,2.500$ e 5.000 ppm e as plantas-controle tratadas com água) e quatro estádios de desenvolvimento (9, 16, 23 e 30 dias após a emergência), com cinco repetições. $O$ herbicida foi aplicado na parte aérea das plântulas de milho. A parte aérea foi coletada às 24, 48 e 72 horas após a aplicação do herbicida e utilizada para a determinação da atividade da GST e do teor de lipoperóxidos. Foi verificado que os teores de lipoperóxidos não foram alterados pelo tratamento com o glyphosate, porém a atividade de GST aumentou na maioria dos tratamentos utilizados, indicando ter ação na degradação do herbicida glyphosate em plantas de milho.
\end{abstract}

Palavras-chave: metabolização de xenobióticos, desintoxicação, inibidor da 5-enol-piruvil shiquimato-3-fosfato sintase (EPSPS).

\begin{abstract}
Glutathione S-transferase (GST, EC 2.5.1.18) plays an important role in the response to stress caused by herbicides in plants; it is considered to be a detoxifying enzyme since it metabolizes a great variety of xenobiotic compounds, by combining them with reduced glutathione, forming substances of low toxicity. Maize (Zea mays) was chosen in this work for showing injury problems when submitted to weed chemical control. This research aimed to determine the alterations in the activity of this enzyme in glyphosate-treated maize plants. The experimental design was completely randomized, in a $4 \times 4$ factorial arrangement, with four treatments (glyphosate at concentrations of 1,000, 2,500 and 5,000 ppm and control plant treated with water) and four developmental stages (9, 16, 23 and 30 days after emergence), with five replicates. The herbicide was applied on the maize plant shoots, which were collected at 24, 48 and 72 hours after herbicide application and utilized for determining the GST activity and lipoperoxide content. It was verified that glyphosate does not change the lipoperoxide content, but increases GST activity for most treatments utilized, indicating its action in the degradation of glyphosate in maize plants.
\end{abstract}

Key words: metabolization of xenobiotics, detoxification, inhibitor of the 5-enolpyruvylshikimate-3-phosphate synthase (EPSPS).

Recebido para publicação em 15.8.2002 e na forma revisada em 11.8.2003.

2 Bióloga, Professora Adjunta. Instituto de Biociências, s/n, 18618-000, Distrito de Rubião Júnior, Botucatu-SP. ${ }^{3}$ Biólogo, Bolsista do CNPq. ${ }^{4}$ Biólogos, Estagiários. ${ }^{5}$ Química Farmacêutica, Estudante do Programa de Pós-Graduação (nível de Mestrado) em Ciências Biológicas. 


\section{INTRODUÇÃO}

Diversos herbicidas sintéticos têm sido desenvolvidos para controlar plantas daninhas em importantes culturas agronômicas. Revisões sobre o mecanismo da ação herbicida têm sido publicadas (Holt, 1993). Herbicidas seletivos são aqueles que matam várias espécies de plantas daninhas sem causar danos significativos às espécies da cultura. A seletividade do herbicida pode, em alguns casos, estar associada às diferenças na absorção do herbicida ou pode ser obtida devido ao método de aplicação (Holt et al., 1995). Entretanto, evidências obtidas nas últimas décadas indicam que freqüentemente o princípio determinante da seletividade do herbicida em plantas é a capacidade destas de metabolizar e, desse modo, ter a capacidade de desintoxicar os herbicidas (Fuerst \& Gronwald 1986; O'Connell et al., 1988).

Glyphosate [N-(fosfonometil) glicina] é um herbicida de amplo espectro, pertencente à classe dos derivados do aminoácido glicina, não-seletivo, que controla plantas mono e dicotiledôneas anuais e perenes. Este herbicida é utilizado extensivamente, sendo aplicado em pós-emergência das plantas daninhas, antes da semeadura ou emergência das culturas (Trezzi et al., 2001). É muito solúvel em água (900.000 $\mathrm{mg} \mathrm{L}^{-1}$ ) e apresenta baixa volatilidade e baixo coeficiente de partição octanol/água $\left(\mathrm{k}_{\mathrm{ow}}=0,019\right)$, indicando reduzida afinidade por lipídios. Seu mecanismo de ação é a atuação sobre a atividade enzimática da 5-enol-piruvil shiquimato-3-fosfato sintase (EPSPS), inibindo a síntese dos aminoácidos aromáticos triptofano, tirosina e fenilalanina (Kruze et al., 2000; Trezzi et al., 2001). Conseqüentemente, as plantas tratadas com glyphosate apresentam deficiência na síntese protéica e de vários outros compostos aromáticos importantes, como vitaminas ( $\mathrm{K}$ e E), hormônios (auxina e etileno), alcalóides, lignina, antocianina e vários outros produtos secundários. Além disso, este herbicida inibe a eficiência fotossintética (Trezzi et al., 2001).

De acordo com Mannervik \& Danielson (1988), existem enzimas que apresentam a capacidade de metabolizar diversos xenobióticos, entre eles os herbicidas, proporcionando, desse modo, a desintoxicação das plantas. Dentre as enzimas, uma das mais consideradas é a glutationa S-transferase (GSTs, EC 2.5.1.18), que catalisa a conjugação de glutationa (GSH) a uma variedade de substratos hidrofóbicos e eletrofilicos, geralmente citotóxicos (Wilce \& Parker, 1994; Kreuz et al., 1996), produzindo conjugados solúveis em água destes xenobióticos, o que reduz sua toxicidade (Cole, 1994; Kreuz et al., 1996).

As GSTs também promovem a conjugação de GSH com produtos endógenos causadores de danos oxidativos, como radicais hidroxila citotóxicos, peróxidos de lipídios de membrana e produtos de degradação oxidativa do DNA, visando sua desintoxicação (Dudler et al., 1991; Barling et al., 1993). De acordo com Levine et al. (1994), o elevado nível de peróxido de hidrogênio induz um grande aumento no mRNA de GST em células de soja. Algumas GSTs também funcionam como glutationa peroxidases, por atuarem diretamente sob tais produtos (Barling et al., 1993).

O presente estudo teve por finalidade avaliar o comportamento da glutationa S-transferase como agente de degradação do herbicida glyphosate em milho, bem como as alterações nos teores de lipoperóxidos, um indicador de desintegração dos sistemas de membranas por peroxidação de lipídios.

\section{MATERIAL E MÉTODOS}

Neste trabalho foram utilizadas plantas de milho (Zea mays).

As sementes de milho foram semeadas numa profundidade de $1,5 \mathrm{~cm}$ em vasos plásticos de $3 \mathrm{~kg}$ de capacidade contendo terra, os quais foram mantidos em casa de vegetação durante todo o experimento. Os vasos foram regados com água, quando necessário.

O delineamento experimental utilizado foi o inteiramente casualizado, em esquema fatorial $4 \times 4$, com quatro tratamentos herbicidas (glyphosate nas concentrações de 1.000, 2.500 e $5.000 \mathrm{ppm}$ e as plantas-controle tratadas com água) e quatro estádios de desenvolvimento (9, 16, 23 e 30 dias após a emergência), com cinco repetições.

Foram utilizados 80 vasos, divididos em quatro grupos (G1, G2, G3 e G4). As semeaduras dos grupos foram realizadas em intervalos de sete dias umas das outras. No momento da 
aplicação dos tratamentos foram usadas plantas de 9, 16, 23 e 30 dias após a emergência (DAE), que correspondeu aos grupos estudados, respectivamente. Cada vaso continha em torno de 20 plantas.

As plantas, nos diferentes estádios de desenvolvimento, foram tratadas com diferentes doses do herbicida glyphosate - Roundup ${ }^{\circledR}$ $(1.000,2.500$ e $5.000 \mathrm{ppm})$. As plântulascontrole foram pulverizadas com água. As diferentes doses do herbicida foram aplicadas com pulverizador costal pressurizado com $\mathrm{CO}_{2}$, com pressão constante de $39 \mathrm{lb} \mathrm{pol}^{-2}$, pontas D6 110.02, velocidade de $4.2 \mathrm{~km} \mathrm{~h}^{-1}$ e volume de $200 \mathrm{~L} \mathrm{ha}^{-1}$.

As amostras da parte aérea das plantas foram coletadas às 24,48 e 72 horas após a aplicação dos tratamentos, sendo a seguir lavadas com água destilada e secas superficialmente com papel-filtro. As amostras foram pesadas, embaladas em sacos plásticos, envolvidas em papel-alumínio, congeladas em nitrogênio líquido e, em seguida, armazenadas em freezer a $-80{ }^{\circ} \mathrm{C}$, para posterior determinação da atividade de glutationa S-transferase e do teor de lipoperóxidos. As quantidades utilizadas das amostras pesadas foram as especificadas em cada método, descritos a seguir.

Para a extração da GST, amostras das folhas das plantas estudadas (1 $\mathrm{g}$ de peso fresco) foram homogeneizadas em almofariz gelado com uma pequena quantidade de areia, em $5 \mathrm{~mL}$ de tampão TRIS-HCl $50 \mathrm{mmol} \mathrm{L}^{-1} \mathrm{pH}$ 7,0 gelado, contendo $20 \%$ de glicerol (v/v), $1 \mathrm{mmol} \mathrm{L}^{-1}$ de ácido ascórbico, $1 \mathrm{mmol} \mathrm{L}^{-1} \mathrm{de}$ ditiotreitol, $1 \mathrm{mmol} . \mathrm{L}^{-1}$ de EDTA, $1 \mathrm{mmol} \mathrm{L}^{-1} \mathrm{de}$ glutationa reduzida e $5 \mathrm{mmol} \mathrm{L^{-1 }}$ de $\mathrm{MgCl}_{2}$. Após duas centrifugações a $4{ }^{\circ} \mathrm{C}(6$ minutos em $12.000 \mathrm{~g}$ e 16 minutos em $26.900 \mathrm{~g}$ ) o sobrenadante foi coletado e armazenado a $-20{ }^{\circ} \mathrm{C}$, para posterior análise da atividade enzimática e do conteúdo de proteína (Knörzer et al., 1996).

A atividade da GST foi analisada de acordo com a metodologia descrita por Wu et al. (1996). A mistura de reação foi composta de $30 \mu \mathrm{L}$ de extrato enzimático, $2.000 \mu \mathrm{L}$ de tampão fosfato de potássio $\mathrm{pH} 6,9100 \mathrm{mmol} \mathrm{L}^{1}, 900 \mu \mathrm{L}$ de glutationa reduzida (GSH) 3,3 $\mathrm{mmol} \mathrm{L}^{-1}$ e $100 \mu \mathrm{L}$ de 1-cloro-2,4-dinitrobenzeno (CDNB) $30 \mathrm{mmol} \mathrm{L}^{-1}$.

A mistura foi incubada à temperatura de $25{ }^{\circ} \mathrm{C}$ e a reação iniciada pela adição de CDNB.
A mudança na absorbância devido à formação do conjugado GSH-CDNB foi medida em espectrofotômetro no comprimento de onda de $340 \mathrm{~nm}$. A razão da conjugação não-enzimática foi determinada pelo uso da mesma mistura de reação sem o extrato enzimático.

O coeficiente de extinção molar de $9,6 \mathrm{mmol} \mathrm{cm}^{-1}$ (Habig \& Jakoby, 1981) foi usado para calcular a atividade da enzima. A atividade específica da GST foi expressa em $\mathrm{nmol} / \mathrm{min} / \mathrm{mg}$ de proteína.

O conteúdo de proteína extraível no tampão utilizado na extração da GST foi estimado pelo método de Lowry et al. (1951), que utiliza o reagente de fenol Seg. Folin-Ciocalteau. Foi utilizada albumina sérica bovina (BSA) como proteína-padrão. As leituras de absorbância foram feitas em espectrofotômetro, no comprimento de onda de $660 \mathrm{~nm}$.

A concentração de lipoperóxidos foi determinada pela técnica do ácido tiobarbitúrico (TBA), de acordo com Satoh (1978). A amostra $(0,2 \mathrm{~mL})$ reage com $0,4 \mathrm{~mL}$ de ácido tiobarbi-

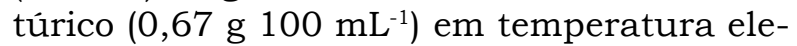
vada $\left(90^{\circ} \mathrm{C}\right)$, e o malondialdeído (MDA) liberado em $\mathrm{pH}$ baixo e temperatura elevada reage com o TBA, formando um complexo extraído em 4,0 $\mathrm{ml}$ de butanol e separado por centrifugação a $3.000 \mathrm{~g}$, apresentando cor rósea de absorção máxima a 532 nm (Heath \& Packer, 1968; Percario et al., 1993).

Os resultados foram submetidos à análise de variância pelo teste de Tukey, a 5\% de probabilidade.

\section{RESULTADOS E DISCUSSÃO}

Na Tabela 1 estão apresentadas as médias dos resultados da atividade da glutationa S-transferase em plantas de milho nos vários estádios de desenvolvimento analisados $(9,16$, 23 e 30 dias após a germinação), tratadas com diferentes doses do herbicida glyphosate (1.000, 2.500 e $5.000 \mathrm{ppm})$, bem como seus respectivos desvios-padrão e a análise de variância dos resultados. Os dados referentes ao teor de lipoperóxidos encontram-se na Tabela 2.

No estádio de desenvolvimento de $9 \mathrm{DAE}$, observou-se que glyphosate aumentou a atividade da GST somente na dose de 1.000 ppm, 
ao passo que no estádio de desenvolvimento de 16 DAE não foram detectadas diferenças entre os tratamentos de glyphosate e a testemunha. No estádio de desenvolvimento de 23 DAE, a atividade da GST foi mais elevada nas plantas de milho aspergidas com o herbicida em todas as doses de glyphosate. Entretanto, não foram detectadas diferenças significativas entre doses. Já no estádio de $30 \mathrm{DAE}$ foi observado aumento da atividade apenas nas doses de 1.000 e 2.500 ppm (Tabela 1).

No estádio de desenvolvimento de $9 \mathrm{DAE}$, ocorreu aumento no teor de lipoperóxidos quando as plantas de milho foram tratadas com as doses de 1.000 e 5.000 ppm de glyphosate.
Nos estádios de desenvolvimento de 23 e 30 DAE, de modo geral, o tratamento com glyphosate não aumentou os teores de lipoperóxidos. Esse aumento só foi observado em plantas aspergidas com glyphosate no estádio de desenvolvimento de 16 DAE (Tabela 2).

A maioria dos trabalhos tem sido realizada para investigar a atividade de GST em milho, em virtude de os herbicidas seletivos metolachlor, alachlor e atrazine, que são muito utilizados nesta cultura, serem metabolizados e, conseqüentemente, transformados, através da conjugação com glutationa. Além disso, o milho contém elevados niveis de GST, representando mais do que $1 \%$ da proteína solúvel total (Cole, 1994).

Tabela 1 - Médias da atividade da glutationa S-transferase ( $\mu \mathrm{mol} / \mathrm{min} / \mathrm{mg}$ de proteína) na parte aérea de plantas de milho (Zea mays), em vários estádios de desenvolvimento (dias após a emergência), tratadas com diferentes concentrações do herbicida glyphosate

\begin{tabular}{|c|c|c|c|c|}
\hline \multirow{2}{*}{$\begin{array}{c}\text { Concentrações de } \\
\text { glyphosate (ppm) }\end{array}$} & \multicolumn{4}{|c|}{ Estádios de desenvolvimento (dias) } \\
\cline { 2 - 5 } & 9 & 16 & 23 & 30 \\
\hline 0 & $33770 \pm 1655,6 \mathrm{~B}$ & $30923 \pm 2089,9 \mathrm{AB}$ & $26284 \pm 2595,2 \mathrm{~B}$ & $34810 \pm 1844,6 \mathrm{~B}$ \\
1000 & $44014 \pm 3851,0 \mathrm{~A}$ & $32618 \pm 2926,7 \mathrm{~A}$ & $38643 \pm 4052,9 \mathrm{~A}$ & $40036 \pm 2897,1 \mathrm{~A}$ \\
2500 & $37546 \pm 3569,6 \mathrm{~B}$ & $26857 \pm 3100,4 \mathrm{~B}$ & $34700 \pm 3604,5 \mathrm{~A}$ & $41390 \pm 2821,3 \mathrm{~A}$ \\
5000 & $35303 \pm 3553,0 \mathrm{~B}$ & $34883 \pm 1687,2 \mathrm{~A}$ & $36046 \pm 3233,6 \mathrm{~A}$ & $34802 \pm 3419,9 \mathrm{~B}$ \\
MDS & 5934,117 & 4563,407 & 6186,714 & 5078,738 \\
CV\% & 8,7 & 8,04 & 10,07 & 7,43 \\
F & 9,483 & 9,048 & 12,234 & 7,591 \\
$\alpha$ & 0,0008 & 0,0010 & 0,0002 & 0,0022 \\
\hline
\end{tabular}

Os valores indicam as médias \pm desvio-padrão de cinco repetições.

Médias seguidas de mesma letra (na horizontal) não diferem significativamente entre si pelo teste de Tukey a 5\% de probabilidade.

Tabela 2 - Teores de lipoperóxidos (nmol $\mathrm{g}^{-1}$ de tecido fresco) na parte aérea de plantas de milho (Zea mays), em vários estádios de desenvolvimento (dias após a emergência), tratadas com diferentes concentrações do herbicida glyphosate

\begin{tabular}{|c|c|c|c|c|}
\hline \multirow{2}{*}{$\begin{array}{l}\text { Concentrações de } \\
\text { glyphosate (ppm) }\end{array}$} & \multicolumn{4}{|c|}{ Estádios de desenvolvimento (dias) } \\
\hline & 9 & 16 & 23 & 30 \\
\hline 0 & $0.9160 \pm 0.082 \mathrm{~B}$ & $1.698 \pm 0.081 \mathrm{~B}$ & $2.238 \pm 0.196 \mathrm{AB}$ & $2.087 \pm 0.143 \mathrm{~A}$ \\
\hline 1000 & $1.206 \pm 0.173 \mathrm{~A}$ & $1.996 \pm 0.243 \mathrm{~A}$ & $2.030 \pm 0.171 \mathrm{BC}$ & $2.228 \pm 0.122 \mathrm{~A}$ \\
\hline 2500 & $1.109 \pm 0.096 \mathrm{AB}$ & $2.006 \pm 0.121 \mathrm{~A}$ & $1.1797 \pm 0.025 \mathrm{C}$ & $2.022 \pm 0.123 \mathrm{~A}$ \\
\hline 5000 & $1.182 \pm 0.041 \mathrm{~A}$ & $2.203 \pm 0.151 \mathrm{~A}$ & $2.313 \pm 0.088 \mathrm{~A}$ & $1.977 \pm 0.252 \mathrm{~A}$ \\
\hline MDS & 0,1975355 & 0,290600 & 0,249933 & 0,302981 \\
\hline $\mathrm{CV} \%$ & 9,88 & 8,12 & 6,59 & 8,05 \\
\hline $\mathrm{F}$ & 7,281 & 8,416 & 14,063 & 2,041 \\
\hline$\alpha$ & 0,0027 & 0,0014 & 0,0001 & 0,1487 \\
\hline
\end{tabular}

Os valores indicam as médias \pm desvio-padrão de cinco repetições.

Médias seguidas de mesma letra (na horizontal) não diferem significativamente entre si pelo teste de Tukey a $5 \%$ de probabilidade. 
Os resultados deste trabalho mostram que a GST participa do processo de metabolização do herbicida glyphosate em milho. Esse fato é mais característico nas menores doses de glyphosate, sugerindo que em doses maiores a enzima não apresenta capacidade para desintoxicar o herbicida. Uotila et al. (1995) também observaram aumentos significativos da atividade da GST em diversas culturas, como trigo, ervilha e milho, tratadas com o glyphosate. Estes autores sugerem que glyphosate induz GST, por estimular a síntese "de novo" desta enzima.

Sarin \& Jain (2000) também postularam que o aumento da atividade da GST induzido pelo glyphosate pode ser explicado por esse mesmo mecanismo e observaram aumento significativo na atividade dessa enzima em três cultivares de amendoim (Arachis hypogaea) com aplicação de glyphosate.

De modo geral, o glyphosate não alterou os teores de lipoperóxidos nas plantas tratadas com o herbicida. O aumento observado nas plantas tratadas com glyphosate em alguns estádios de desenvolvimento pode ser decorrente da situação de estresse induzida pelo herbicida e não da produção de espécies reativas de oxigênio, visto que o mecanismo de ação do glyphosate não envolve esse processo.

Pelos resultados apresentados, pode-se concluir que a glutationa S-transferase atua na degradação do herbicida glyphosate em plântulas de milho, quando este é aplicado em baixas concentrações.

\section{LITERATURA CITADA}

BARLING, D. et al. A glutathione S-transferase with glutathione peroxidase activity from Arabidopsis thaliana: molecular cloning and functional characterization. Europ. J. Biochem, v. 216, p. 579-86, 1993.

COLE, D. Detoxification and activation of agrochemicals in plants. Pest. Sci., v. 42, p. 209-222, 1994.

DUDLER, R. et al. A pathogen-induced wheat gene encodes a protein homologous to glutathione S-transferases. Mol. Plant Microbe Interact., v. 4, p. 14-18, 1991.

FUERST, E. P.; GRONWALD, J. W. Induction of rapid metabolism of metolachlor in sorghum (Sorghum bicolor) shoots by CGA-92194 and other antidotes. Weed Sci., v. 34, p. 354-361, 1986.

HABIG, W. H.; JAKOBY, W. B. Assays for determination of glutathione S-transferase. Methods Enzymol., v. 77, p. 398-405, 1981.
HEATH, R. L.; PACKER, L. Photoperoxidation in isolated chloroplasts. I. Kinetic and stoichiometry of fatty acid peroxidation. Arch. Biochem. Biophys., v. 125, p. 189-98, 1968.

HOLT, J. S. Mechanisms and agronomic aspects of herbicide resistance. Ann. Rev. Plant Physiol. Plant Mol. Biol., v. 44, p. 203-229, 1993.

HOLT, D. C. et al. Characterization of the safener-induced glutathione S-transferase isoform II from maize. Planta, v. 196, p. 295-302, 1995.

KNÖRZER, O. C.; DURNER, J.; BÖGER, P. Alterations in the antioxidative system of suspension-cultured soybean cells (Glycine max) induced by oxidative stress. Physiol. Plant., v. 97, p.388-396, 1996.

KREUZ, K.; TOMMASINI, R.; MARTINOIA, E. Old enzymes for a new job. Herbicide detoxification in plants. Plant Physiol., v. 111, p. 349-53, 1996.

KRUZE, N. D.; TREZZI, M. M.; VIDAL, R. A. Herbicidas inibidores da EPSPS: Revisão de literatura. R. Bras.

Herbicidas, v. 1, n. 2, p. 139-46, 2000.

LEVINE, A. et al. $\mathrm{H}_{2} \mathrm{O}_{2}$ from the oxidative burst orchestrates the plant hypersensitive disease resistance response. Cell, v. 79, p. 583-93, 1994.

LOWRY, O. H. et al. Protein measurement with folinphenol reagent. J. Biol. Chem., v. 193, p. 265-75, 1951.

MANNERVIK, B.; DANIELSON, U. H. Glutathione transferases: structure and catalytic activity. CRC Crit. Ver. Biochem., v. 23, p. 283-337, 1988.

O'CONNELL, K. M.; BREAUX, E. J.; FRALEY, R. T. Different rates of metabolism of two chloroacetanilide herbicides in Pioneer 3320 corn. Plant Physiol., v. 86, p. 359-363, 1988.

PERCARIO, S.; CAMARGO, C.; FELIPPE JR., J. Avaliação dos radicais livres pela dosagem da peroxidação lipídica: padronização da técnica. In: CONGRESSO BRASILEIRO DE CLÍNICA MÉDICA, 2., São Paulo, 1993. Anais... São Paulo: 1993. p. 116.

SARIN, N. B.; JAIN, M. Glyphosate-induced increase in glutathione S-transferase activity and glutathione content in groundnut. In: INTERNATIONAL WEED SCIENCE CONGRESS, 3., Foz do Iguaçu, Brasil. Anais... Foz do Iguaçu: 2000. p.121.

SATOH, K. Serum lipid peroxide in cerebrovascular disorders determined by a new colorimetric method. Clin. Chim. Acta, v. 90, p. 37-43, 1978.

Planta Daninha, Viçosa-MG, v.21, n.2, p.307-312, 2003 
TREZZI, M. M.; KRUZE, N. D.; VIDAL, R. A. Inibidores de EPSPS. In: VIDAL, R.A.; MEROTTO JR., A. (Eds.)

Herbicidologia. Porto Alegre, 2001. p. 37-45.

UOTILA, M.; GULLNER, G.; KÖMIVES, T. Induction of glutathione S-transferase activity and glutathione level in plants exposed to glyphosate. Physiol. Plant., v. 93, p.689694, 1995.
WILCE, M. C.; PARKER, M. W. Structure and function of glutathione S-transferases. Biochim. Biophys. Acta, v. 1205, p. 1-18, 1994.

WU, J.; OMOKAWA, H.; HATZIOS, K. K. Glutathione Stransferase activity in unsafened and fenclorim-safened rice (Oryza sativa). Pestic. Biochem. Physiol., v. 54, p. 220229, 1996. 